\title{
Problems of Application of the Environmental Legislation to the Maintenance and Construction of Urban Buildings and Structures: the Russian Experience
}

\author{
Igor' Petrovich Pryadko ${ }^{1 *}$ and Igor' Michajlovich Lebedev ${ }^{1}$ \\ ${ }^{1}$ Moscow State University of Civil Engineering, Yaroslavskoye sh. 26, Moscow, 129337, Russia
}

\begin{abstract}
In the paper, the co-authors analyze the legal methods applied to create the biosphere compatible urban environment. The co-authors analyze a legal case on the calculation of maximal acceptable emmissions in the environmental section of a design project. The co-authors assess the legal consequences of termination of agreements through legal proceedings. The co-authors address the cases of practical application of the Russian regulatory acts. The co-authors also analyze the binding requirements applied to the environmental protection documentation.
\end{abstract}

\section{Introduction}

Planet Earth, or the living environment for homo sapiens, is often defined as our home, and environmental science is the science dealing with the human environment; therefore, this science deals with our home. At the same time, Earth is often called the workshop for human beings, or the place where humans can apply the skills to transform the environment. In their practical activity, humans of the 21 st century cannot ignore the conclusions derived by the environmental science, which has developed into a flexible network of disciplines. Construction and operation of buildings/structures represent those practical activities that cannot ignore environmental science. In this article, the co-authors use a legal case to analyze the court decisions dealing with the environmental consequences of economic activities.

Today both business and production activities of humans (including construction and maintenance of buildings) are focused on the development of a clean biosphere compatible environment. Any operations performed by housing construction and maintenance organizations must be governed by the law to ensure optimal and/or acceptable living conditions for humans. If a city or a town accommodates residential housing, the damage to the urban environment turns inevitable. Pollutants are also emitted in the process of operation of industrial structures. The operation of urban housing buildings also involves grave consequences for the natural environment. The specialists, who are responsible for their operation, have an opportunity to reduce the per cent content of industrial and household dust and hazardous emissions, produced by the household waste, including methane and other

${ }^{*}$ Corresponding author: Priadcko.igor2011@yandex.ru 
pollutants, in the urban atmosphere so that they did not exceed the acceptable limits. The mission of this research project is to analyze the legal practice dealing with the operation of buildings, in the context of environmental law.

Specialized services agencies, engaged in environmental consulting and responsible for the issuance of environmental reports on behalf of small and mid-size business enterprises, including those engaged in the operation of urban buildings, are responsible for the identification of threshold values of pollutants emitted into the urban atmosphere. The principal business of environmental consulting organizations consists in the identification of maximal amounts of solid waste and other pollutants authorized for dumping. Most of these organizations provide their services on a commercial basis.

The local microclimate and the condition of the geosphere shells in specific urban districts depend on the effective operation of these environmental consuting companies. Any malfunctions in their operation, their failure to fulfil the responsibilities can deteriorate and deteriorates the environmental condition of construction facilities. Moreover, cases of failure by environmental supervision companies to fulfil their responsibilities are often reviewed in court, if these companies are sued by the enterprises that use their services.

The main objective to be attained by the co-authors is to employ the court practice to substantiate the following statement: improvement of the environmental provisions of the construction law is only possible, if accompanied by the proactive involvement of the civil society and impeccable operation of the court system. Any conflicts, occurring in the construction industry due to the violation of the environmental law, are embodied in court decisions. Therefore, the co-authors use the decision issued by the Moscow Arbitration Court in the case of the Moscow State University of Civil Engineering versus Ecolis limited liability company. Problems of environmentally safe construction and maintenance of buildings/structures are considered differently in the second part of this article. There the coauthors assume that, apart from the state, members of the public are involved in the environmental protection in the 21 st century. The novelty of this research consists in the conclusion concerning the involvement of the general public in the environmental protection of residential areas, constructed in compliance with the standards applicable to urban construction facilities.

The atmosphere of megalopolises, analyzed in the first part of our article, is particularly susceptible to the penetration of pollutants. Today acceptable limits for emmissions are set by the Russian legislation, including threshold concentrations of pollutants in the atmosphere and other geosphere shells. The findings of several environmental research projects serve as the basis for the regulatory requirements, specified in the laws used by the courts. They are also considered in this article.

\section{Materials and methods}

The theoretical materials, pre-studied by the co-authors, include urban ecology data. Pollution of the surface air in major cities, mostly in the areas close to highways and industrial enterprises, represents a most complex problem of urban ecology. During rush hours, the content of carbon dioxide exceeds the accaptable values 50 -fold, the content of nitrogen oxide exceeds the acceptable values 150 -fold, and the content of volatile hydrocarbons exceeds the acceptable values 1,500-fold. Dust and silicon oxide, when accumulated in the air, generate photochemical smog. Moreover, any construction sites in megalopolises tend to increase the dust content in the surface air of the atmosphere in urban suburbs, let alone the accumulation of heat energy close to the Earth surface, and this process causes the climate change. Ozone, that protects us from strong solar emissions at the altitude of 25 kilometers, converts into a dangerous pollutant when it reaches the surface layer of the atmosphere; it causes a variety of diseases. The main reasons for air contamination consist in (1) the concentration of 
residential houses in cities and towns and (2) human waste generated in the cities (according to UNESCO, the majority of earthians live in cities and towns). These factors produce an immediate impact on the condition of the atmosphere and rise the content of such pollutants as methane, carbon dioxide, etc. According to Article 1 of the Federal Law On Protection of the Atmosphere», «The emission of hazardous substances (pollutants) into the atmosphere by fixed sources of environmental pollution is acceptable pursuant to the permit, issued by the local agency of the competent Federal authority in charge of environmental protection, by the executive authorities of subjects of the Russian Federation in charge of envrionmental protection in accordance with the procedure set by the RF Government. The permit to emit hazardous substances (pollutants) into the atmosphere sets the maximum permissible emmissions and other conditions that ensure the protection of the atmosphere». [1] Organizations enter into contracts for the identification of tailored values of maximum permissible emmissions. The environmental protection documentation is registered by the Federal executive authorities of the RF subjects, responsible for the issuance of permits and certificates to legal entities. Each organization that owns real estate in urban areas, must have these documents officially issued in its name. Civil activists initiate environmental campaigns, including motor rallies for vehicles that consume ecological fuel. [2]

The systemic nature of environmental actions becomes a binding condition of survival for the present-day urban social community. Numerous examples illustrate the involvement of the civil society into environmental protection actions. In 2017, which was declared the Year of Ecology, several actions were held in the Moscow metropolitan area: The Shore Descent, when the banks of the Klyazma river, Lake Senezh, Yubileiny pond were cleaned ; The Full-scale Cleaning project, its mission was to liquidate unauthorized waste accumulation sites, including construction debris sites (it was held together with the activists of the All-Russian People's Front, the environmental action entitled The Forest of Victory was held to restore parks and public gardens in the towns located in the Moscow Metropolitan area. Civil activists have cleaned the Pekhorka and Malashka rivers not far from Balashikha, and the Bykovka river not far from the town of Zhukovsky. Representatives of the civil society «make raids» to identify and prevent illegal waste deposits, to check the removal of construction debris and household waste. In 2017, 129 gardeners' non-commercial partnerships were checked and 52 campaigns were held. [3].

All of these actions may only turn efficient if supported by the law, or if they are approved by the effective environmental legislation, and also if environmental consulting companies timely fulfil their responsibilities in full.

In the article, the co-authors used the regulatory acts of the Russian environmental law as the source materials. The objective of the regulatory acts, used by the co-authors, is to protect natural sites and geosphere shells located within the area of responsibility of legal entities operating within the limits of the towns. The articles of the Civil Code of the Russian Federation, Federal laws, materials of court proceedings serve as the legal framework for this research project. The co-authors have employed the comparative approach, whereby the legal acts are analyzed in comparison with their practical application. In the article, the law enforcement practice, or the decision issued by the Moscow Arbitration court, is analyzed. The co-authors have also employed the retrospective analysis of the sources, deduction, induction and analogy. The data of the environmental monitoring, performed within city limits, are used to analyze the condition of the environment there. The final method involves the analysis of the facts, mentioned in popular science editions on social ecology. [4] They include the data generated by the Central Administration for Hydrometeorological and Environmental Monitoring («the Central Administration») and published in the media, on the website of the Central Administration and the Ministry of Civil Defense, Disaster Management and Emergency Response. These institutions track changes in the composition 
of the outdoor air in Moscow districts and towns of Metropolitan Moscow [5], and publish information on the accumulation of pollutants in the water bodies and the lithosphere.

\section{Results}

The co-authors analyze the environmental support of the process of maintenance and operation of buildings and structures within city borders. The result of this research project consists in the analysis of a specific legal case employed to compare the practical management of natural resources in the cities and towns with the general provisions of the envrionmental law, namely, with the provisions of the Civil Code of the Russian Federation. The law identifies the entities and persons responsible for the excess of maximum admissible emmissions of hazardous and harmful substances into the atmosphere. According to the laws of the Russian Federation, whenever an agreement is made for the identification of maximum admissible emmissions, the customer submits a request for proposal and, having signed the services provision agreement, the customer makes a prepayment to the services provider. The prepayment amount is needed for the services provider to be able to initiate the provision of services (their first stage), as the calculation of draft maximum admissible emmissions has several stages. A package of documents must be delivered to the services provider both purusant to respective agreements and the RF Civil Code. Let us address the text of the Civil Code: « Under the contract of repayable rendering of services the executor shall undertake to render services (to perform certain actions or carry out certain activity) according to the customer's assignment, while the customer shall undertake to pay for these services.» [6]

Let's address a specific case, that is, the performance of the responsibilities pursuant to the agreement between the State University of Civil Engineering and Ecopolis limited liability company. The Moscow State University of Civil Engineering is a major institution of civil engineering education that has several buildings in different districts of the capital. The university is engaged in versatile educational, production and economic activities associated with civil engineering. The University's property includes the buildings and structures located in Spartakovskaya street. One of these builldings (located at 2/1 Spartakovskaya st.) represents a monument of architecture; it's a famous mansion formerly owned by Musin-Pushkin, known in the literature as the Razgulai house. Same as any other monument of architecture, this building is sensitive to the condition of the environment, while the preservation of its walls and bearing structures depends on the reduced content of chemically active pollutants which can cause corrosion and destroy this historic building or its parts. Ecopolis limited liability company, that acted as the defendant in court, was also responsible for the issuance of environmental reports on behalf of small and mid-size business companies and prepared statistical monitoring documents concerning formation, deactivation, dumping and use of waste, generated in the course of the economic activity performed by the organizations acting in the capacity of users of natural resources. This company failed to comply with the dates specified in the agreement and to perform the responsibilities assumed pursuant to this agreement. This circumstance forced the plaintiff (the University) to file a lawsuit.

The main criterion of jurisdiction of arbitration courts over a case consists in the emergence of a debatable material legal relation as part of entrepreneurial or other economic activity. [7] Every party, seeking juridical protection, «must prove the relevancy of its statements in court in the form of judicial evidence» [8]. In its decision, the Moscow Arbitration Court, «having listened to the representative of the plaintiff and having studied the written evidence $»$, complied with the demand of the plaintiff. [9].

According to the case materials, on March 11, 2016, the plaintiff (the customer) and the defendant (the company, or the services provider) entered into Agreement № 302-160 00, pursuant to which the customer was to accept and to pay for the services provided by the 
company. The services consisted in the environmental support of the building located at $2 / 1$ Spartakovskaya st., Central Administrative District. The services were provided pursuant to Assignment 1 (Exhibit 1 to the Agreement). Pursuant to the Agreement, the company was to have the maximal admissible emissions approved by the Federal Budgetary Institution of Healthcare, Federal Service for the Supervision over Protection of Consumers' Rights and Human Welfare, by the Department of Environmental Management and Nature of Moscow. In paragraph 2.1. of the Agreement and in Exhibit 2 to the Agreement the parties agreed upon the total amount payable for the services provided by the company (220 thousand roubles).

Let's address the essence of the case. It consists in the failure to perform the responsibilities assumed pursuant to the Agreement. The responsibility for this failure is specified in the Civil Code and the environmental laws of the Russian Federation. Section 3.1.1. of the Agreement and Exhibit 4 to the Agreement say that the date of initiation of services provision represents the date of delivery of all necessary documents to the company by the customer. Given the fact, that pursuant to the letters of March 16, 2016 and April 7, 2016, these documents was delivered to the executives of Ecopolis limited liability company, April 7, 2016 was the date of initiation of services provision. The services specified in sections 1, 5, and 7 of Exhibit 1 to the Agreement were to have been provided by the defendant by April 30, 2016. According to the court materials, the defendant did not fulil its responsibilities, although the company had 22 days to do it (as the Agreement was made on April 7, 2017). No responsibilities were fulfiled by the defendant as of April 13, 2017. The only item of services was provided by the defendant, and it took the defendant 107 days instead of 22 day to provide the item of services, according to the Work Completion Certificate № 125 of August 24, 2016. When analyzing the activities of the services provider, whose work was found inacceptable, we should draw attention to the fact that the absence of control over the pollutants arriving into the surface layer of the atmosphere is potentially dangerous both in terms of preservation of the urban biota, and in terms of human health. The arguments of the plaintiff are supported by the provisions of the Civil Code, as pursuant to Article 309, responsibilities must be duly delivered in accordance with the pre-agreed terms and provisions of the law.

Pursuant to Article 314 of the RF Civil Code, the obligation shall be subject to discharge within the term determined by the parties. Article 779 of the RF Civil Code says that under the contract of repayable rendering of services the executor shall undertake to render services (to perform certain actions or carry out certain activity) according to the customer's assignment, while the customer shall undertake to pay for these services. According to section 9.1. of the agreement, it can be terminated in a court of law, in case of substantial violation of its terms by the services provider. A long delay in the provision of services by the defendant in the absence of any objective excuses means a violation of the terms and conditions of the Agreement and involves the repayment of damages by the defendant; therefore, the defendant loses the right to a substantial part of its renumeration agreed upon at the time of the Agreement execution.

As the defendant refused to voluntarily terminate the Agreement, even though the defendant violated its terms and conditions, the Agreement could be terminated in a court of law. The University made an advance payment to the services provider in the amount of 105000 roubles. Pursuant to section 2 of Article 405 of the RF Civil Code, the amount, paid as an advance payment, must be repayable by the company for the benefit of the customer.

And now let us address the financial consequences of the court's decision. The plaintiff issued a claim to the defendant to complete the pre-trial dispute resolution procedure, and this claim was ignored by the defendant. As the case materials confirm that the services were not provided by the defendant on time, while the defendant could not prove the opposite, the prepayment amount must be returned by the defendant to the plaintiff. The state duty paid by the plaintiff must be recovered from the defendant pursuant to section 1 of Article 110 of the 
Arbitration Procedure Code of the Russian Federation. Apart from the responsibilities assumed pursuant to the Agreement, the customer is responsible for the identification of maximal acceptable emmissions. In the meantime, executive authorities are not obliged to enter into the details of problems arising in the course of provision of services according to the Agreement. Indeed, failure by the environmental consulting companies to fulfil their responsibilities causes losses and is harmful for the urban environment.

\section{Discussion of Protection of the Urban Air Basin}

Let's switch to the discussion section of our research, that is, the study of the problme of getting the civil society involved in thre protection of the air basin within city limits. The involvement of urban residents in environmental actions is debatable. In this paragraph we will address the involvement of urban communities in nature protection actions that serve as a matter of dispute between different parties. It is noteworthy that the monitoring of the condition of the aerial environment in a megalopolis represents a labour-intensive undertaking that requires a set of specialized equipment that public organizations seldom have at their disposal. Air sampling needs specialized pumps. This process can take up to 20 minutes. [10] Then it will take two or three days to analyze the air samples. If the odour is not permanent, or the monitoring takes a long period of time, the expert stays in his lab truck on duty. Any independent examination is performed on a fee basis. It may cost up to 15000 -20000 roubles. Therefore, any independent examination needs the efforts to be exerted by a group of people. The same pressure group made a construction company responsible for the emission of aggressive smoke into the atmosphere of Rupasovo, a small village near Moscow.

Besides, we can take advantage of the opportunity to get urban residents indirectly involved in protection of the air basin. Civil activists can get involved in the indoor cleaning of buildings and structures that may have potentially hazardous substances inside. Urban residents can dial the hotline to inform the urban administration about the extreme concentration of pollutants in the atmosphere, about combustion products or strange odours. Local media agencies often serve as intermediaries between urban authorities and representatives of the civil society. In the first paragraph of this article, the co-authors provided examples of involvement of officers of environmental organizations in nature management actions. Residents of houses, located close to production facilities, are deeply concerned with the condition of the urban environment. They can file their lawsuit, having obtained a report of independent examination of the air. If the lawsuit is filed in court, the report of the independent examination must be considered in the manner prescribed by the law. The inappropriate implementation of an agreement by the services provider can cause the agreement to be terminated and sanctions to be imposed against the default party. However this fact does not release the customer from performance of the responsibilities to register maximal admissible emmissions in the due time according to the law. Executive authorities are authorized to apply restrictive and preventive measures in order to prevent and/or liquidate the consequences of violations committed by legal entities and natural persons in their activities. [11] The example, provided in the fifth paragraph, serves as the illustration of harmful consequences for the urban environment.

\section{Conclusions}

The programme for maximal admissible emmissions serves as the basis for the issuance of permits and for the payment of environmental fees together with the state registration fee, 
because the calculation section of the environmental fee is composed of the waste recycling scedule and maximal values of waste amounts.

Correct values of environmental fees depend on the accuracy of annual waste amounts. Therefore, if the maximal amout is exceeded, the fee goes up five-fold, and if the permits for emmissions and maximal admissible amounts are unavailable, the fivefold increasing coefficient is applied to the whole amount of pollutants.

No agreement, even if terminated by the court decision, releases the defendant from the responsibility to pay the damages incurred by the customer in the form of fines charged by the executive authorities of the RF subject, and it means that according to the agreement, the company must deliver the result of work to the customer. Consequently, the customer is entitled to request that the company reimburses the amount of due damages.

No trash - no mess! This set expression seems quite fair. "No trash" means that environmental consulting companies must fulfil their responsibilities, while legal norms do not let the industrial waste pollute our "common home", planet Earth. Effective laws of the Russian Federation oblige enterprises and institutions to comply with the regulatory requirements in terms of maximal hazardous emissions.

\section{References}

1. Federal Law № 96-FZ of May 04, 1999 On Protection of the Atmosphere Air, ColsultantPlus database. Date of access: 20.11.2017.

2. E. Felippe, Metro,67, 2 (2017)

3. The Moscow Region Today, 3(3), April 3 (2017)

4. Social Ecology (Moscow, Yurist Publ, 2016)

5. The Week of the Moscow Region, 23(201)

6. The Civil Code of the Russian Federation. Part II. ColsultantPlus database. Date of access: 20.11.2017

7. L. Azamatova, T. Maksyutov, Problems of the Law Enforcement Practice against the Background of Integration of Supreme Courts (Moscow, Yurist Publ, 2017)

8. V. Molchanov, The Court Evidence in the Future Unified Civil Process Code of the RF (Moscow, Yurist Publ, 2017)

9. Decision on Case A 40-135038/17-56-1065 URL: http://www.msk.arbitr.ru Date of access: 22.11.2017.

10. M. Makeeva, Bitumen Dust Kills Our Health, Soroka Mytischi, 11.06.2013

11. Resolution № 322 issued by the Government of the Russian Federation On Approval of Provisions of the Federal Service in Charge of Supervision over protection of Consumers' Rights, ColsultantPlus database. Date of access: 20.11.2017. 